J. J. MORALES DE CANO

J. ROMERO RUIZ

A. GARCÍA RUZAFA

A. FERNÁNDEZ SABATÉ

Servicio de Cirugía Ortopédica y Traumatología Ciudad Sanitaria y Universitaria de Bellvitge.

\section{Estudio experimental del relleno de cavidades óseas con hidroxiapatita asociada a colágeno}

\author{
Experimental study of filling bone \\ cavities with collagen-associated \\ hydroxyapatite
}

\section{Resumen}

La cirugía ortopédica y maxilo-facial necesita realizar en muchas ocasiones resecciones masivas de tejido óseo. Esto ha hecho que se hayan propuesto la utilización de materiales inertes como sustitutos óseos, gracias a la habilidad que tienen de permitir la regeneración del hueso, tanto en el campo de la medicina como de la odontología. Nuestro trabajo tiene por objetivo estudiar un biomaterial compuesto de hidroxiapatita asociado a colágeno como material de sustitución ósea (Collapat de OSTEO AG) en forma de esponjas, con un peso de $500 \mathrm{mg}$ y de un tamaño de $35 \times 30 \times 6 \mathrm{~mm}$. Se han intervenido 50 animales de experimentación (conejo Albino de Nueva Zelanda), divididos en dos grupos, el grupo I o grupo control estaba comprendido por 16 animales. Los animales de este grupo fueron intervenidos quirúrgicamente realizándose una cavidad a nivel metafisodiafisario en el fémur y otra en la tibia, pero en ninguna de las cavidades se realizaron implantes. Los animales del grupo II o grupo estudio estaban comprendidos por 34 animales, a los que se les realizó la misma intervención, pero se le implantó una esponja de hidroxiapatita-colágeno de las dimensiones antes descritas, en cada una de las cavidades. El estudio ha demostrado una regeneración ósea de la cavidad rellenada a expensas de la rápida reabsorción del colágeno, y de una lenta reabsorción de la hidroxiapatita.

Palabras clave: Sustitutos óseos. Relleno de cavidades. Hidroxiapatita. Colágeno.

\begin{abstract}
Summary
Orthopedic and maxillofacial surgery often requires massive resection of bone tissue. The use of inert materials as bone sustitutes has been proposed because of they facilitate bone regeneration in medical and odontological applications. We studied a biomaterial consisting of hydroxyapatite associated with collagen as a bone substitute (Collapat of OSTEO AG), which is available as $500 \mathrm{mg}$ sponges measuring $35 \times 30 \times 6 \mathrm{~mm}$. Fifty experimental animals (New Zealand albino rabbit) were divided into two groups: group I, the control group, had 16 animals. These animals underwent surgery in which metaphyseal-diaphyseal cavities were made in femur and tibia and left unfilled by implants. Group II, the study group, had 34 animals which underwent the same operation, but each cavity was filled with implants of hydroxyapatite-collagen sponges of the dimensions described above. Our study showed bone regeneration of the filled cavities as a result of rapid collagen resorption and slow hydroxyapatite resorption.
\end{abstract} Key words: Bone substitutes. Cavity silning. Hydroxyapatite.
Collagen.

\section{Introducción}

La cirugía ortopédica y maxilo-facial necesitan realizar en muchas ocasiones resecciones masivas de tejido óseo (tumores, infecciones, cirugía protésica, etcétera), esto nos obliga a dejar cavidades óseas externas debilitadas por la pérdida del hueso resecado. Estas cavidades presentan una disminución en la resistencia

Correspondencia:

J. J. MORALES DE CANO. Balmes, 395. 1º-2 08022 Barcelona. mecánica y por lo tanto son tributarias de complicaciones, como: aparición de fracturas patológicas, reactivaciones sépticas, aflojamientos precoces en la cirugía endoprotésica, etc.

Para evitar estas complicaciones podemos recurrir a la utilización de injertos óseos. El injerto más usado es el autoinjerto, pero éste tiene la limitación del propio paciente, no siendo suficiente para rellenar cavidades extensas. El otro tipo de injerto habitualmente usado es el aloinjerto, aunque su utilización está muy desacreditada debido al alto índice de reacciones de 
hipersensibilidad que pueden producir, así como la posibilidad de servir de vehículos de transmisión de enfermedades infecciosas. Por otra parte, la utilización de los bancos de hueso para obtención de aloinjerto representa un coste económico importante para su mantenimiento ${ }^{6}$.

Esto ha hecho que en los últimos años algunos autores hayan propuesto como sustitutos óseos, la utilización de materiales sintéticos gracias a la habilidad que tienen de permitir la regeneración del hueso, tanto en el campo de la medicina como de la odontología 3, 11, 16, 17 . Los materiales más utilizados con este fin son los derivados de los fosfatos cálcicos, estos son usados para la reparación ósea por su biocompatibilidad, y por sus características físicas y químicas similares a la hidroxiapatita componente de la matriz ósea $3,7-10,12,16,17,24,29,30,32$. El fosfato cálcico está basado en la hydroxiapatita estequiométrica obtenida del coral en base a un proceso de cambio hidrotermal, con una estructura interna microporosa similar al hueso ${ }^{12,13,32}$. La estructura micropórica tiene unos poros de un diámetro de entre 190 y $230 \mathrm{mi}-$ crómetros, preparados para permitir el paso de vasos y depósito de hueso. Están suficientemente descritos los eventos bioquímicos y celulares que se producen en formación ósea hetereotópica que se produce inducida por el implante subcutáneo de matriz ósea desmineraliza$\mathrm{da}^{3,9}, 19,20,27,28,41$.

La propiedad más buscada en estos biomateriales ha sido la osteoinducción, es decir, la capacidad de estimular la formación de hueso. Sin embargo, no se ha podido demostrar esta propiedad en ninguno de los materiales estudiados. Parece ser que la capacidad de osteoinducción estaría reservada a las proteínas formadoras de hueso (bone morphogenetic protein) descritas por Urist, y que forman parte de la matriz ósea ${ }^{39,40}$, en contra de las teorías de Takoaka y Glass ${ }^{11,37}$. Otras proteínas de la matriz ósea que en un principio se pensó que también actuarían como inductoras de la osteogénesis se han descartado recientemente, como es el caso de la osteogenina ${ }^{33-36}$.

Nuestro trabajo tiene por objetivo estudiar un biomaterial compuesto de hidroxiapatita asociado a colágeno como material de sustitución ósea.

\section{Material y métodos}

\section{Material de implante}

Utilizamos la hidroxiapatita en forma de gránulos de un grosor de 30 micras, unidos mediante una red de colágeno, dado un aspecto de esponja (Collapat, fabricado por OSTEO AG). El colágeno es obtenido de la piel del cerdo por digestión con tripsina y posteriormente purificado. La distancia entre los gránulos de hidroxiapatita es de 100 micras, para permitir el crecimiento del tejido óseo a través de ellos (Fig. 1). Estas esponjas de hidroxiapatita y colágeno son de un peso de $500 \mathrm{mg}$ y de un tamaño de $35 \times 30 \times 6 \mathrm{~mm}$.

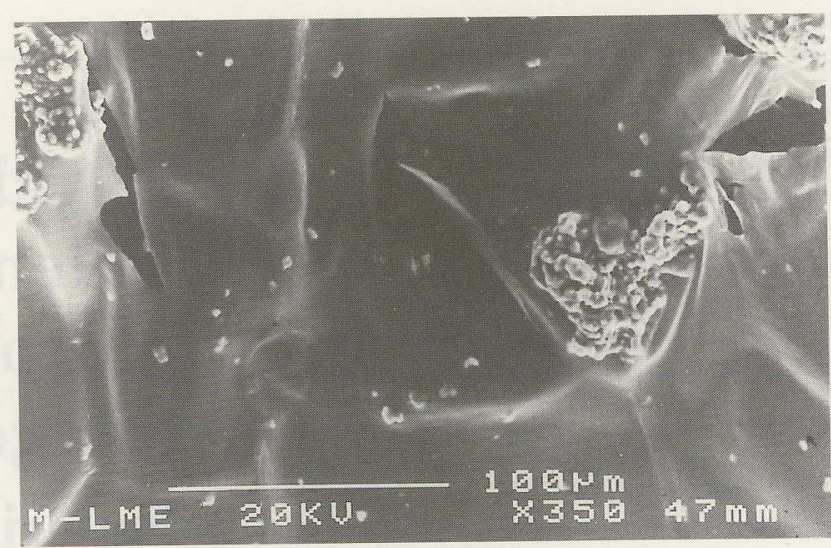

FIG. 1.-Aspecto de las esponjas de Collapat en el microscopio electrónico de barrido X 350 .

El material es esterilizado previamente a la intervención mediante rayos gamma a una dosis de 25 KGray, en el Centro Aragongamma.

\section{Animal de experimentación}

El estudio se realizó en el conejo albino de Nueva Zelanda, todos machos, con edades comprendidas entre 4 y 5 meses, con un peso de 3,5-4 Kg. Los animales fueron cuidados en el estabulario con las normas habituales (temperatura de la habitación de $22^{\circ} \mathrm{C}$, humedad relativa de $55,5 \%$, cambio del aire 20 veces/hora).

Intervenimos 50 animales, divididos en dos grupos, el grupo I o grupo control, comprendido por 16 animales. Los animales de este grupo fueron intervenidos quirúrgicamente realizándose una cavidad a nivel metáfiso-diafisaria en el fémur y otra en la tibia, pero en ninguna de las cavidades se realizó implante. Los animales del grupo II o grupo estudio estaban comprendidos por 34 animales, a los que se les realizó la misma intervención, pero se le implantó una esponja de hidroxiapatita-colágeno de las dimensiones antes descritas, en cada una de las cavidades.

\section{Técnica quirúrgica}

Todos los animales fueron intervenidos bajo anestesia (ketolar, atropina y diacepán). Se realizó una incisión interna a nivel del tercio distal femoral con abordaje entre el vasto medial de la zona metáfisisdiafisaria del fémur, y otra a nivel metafisario de tibia, mediante una broca de $2 \mathrm{~mm}$, con unas dimensiones de $15 \mathrm{~mm}$ de diámetro. Estas cavidades fueron rellenadas mediante el material sujeto de estudio (Fig. 2). Al finalizar la intervención quirúrgica la extremidad intervenida de los animales fue inmovilizada mediante un vendaje de yeso pelvipédico. 


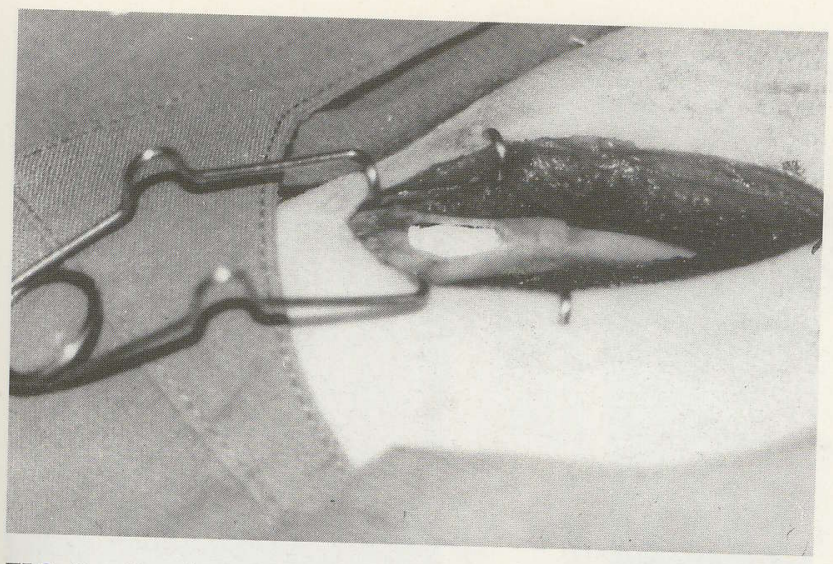

FIG. 2.-Implantación del material en el fémur del animal de experimentación.

Los animales fueron sacrificados en tiempos diferentes, entre 3 días y 5 semanas los animales pertenecientes al grupo I, y entre 3 días y 12 semanas los animales pertenecientes al grupo II.

\section{Estudios postoperatorios}

Desde el momento de la intervención y hasta el sacrificio de los animales, se realizó el seguimiento de los siguientes parámetros, para evaluar los resultados de los implantes:

\section{Determinaciones bioquímicas:}

- calcemia

- uremia

- creatinina

- determinación de fosfatasas alcalinas.

Estas determinaciones se realizaron cada 3 días las primeras 2 semanas, y a partir de este momento se hicieron semanalmente hasta el sacrificio del ani-
$\mathrm{mal}$.

2. Estudio radiográfico: se realizaron controles radiográficos cada quince días desde el momento de la intervención hasta el sacrificio de los animales.

3. Estudio histológico: al producirse el sacrificio de los animales. Se realizó mediante: - estudio histológico descriptivo con hueso sin
decalcificar.

- estudio histomorfométrico con hueso sin decalcificar, analizando:

- superficie de material implantado

- superficie de hueso formado.

- estudio ultraestructural de los macrófagos existentes, así como de los osteoblastos.

\section{Tratamiento estadístico de los resultados}

Los datos obtenidos en los resultados fueron tratados estadísticamente mediante los test de Chi-cuadrado, T de Student y test de Wilcoxon, fijándose la significación estadística en $\mathrm{p}<0,05$.

\section{Resultados}

\section{Determinaciones bioquímicas}

Los resultados de las determinaciones de calcio en suero nos dieron en los animales del grupo I cifras comprendidas entre 13,98 y 15,30 mg/dl. En los animales del grupo II los valores obtenidos fueron entre 11,80 y $15,90 \mathrm{mg} / \mathrm{dl}$. Todos los resultados nos mostraron valores dentro de la normalidad. El tratamiento estadístico de estas determinaciones entre los animales del grupo I y II fue de $p>0,05$, por lo tanto sin diferencia estadísticamente significativa.

Los datos obtenidos en las determinaciones de urea en los animales del grupo I están comprendidas entre 28,9 y $36,1 \mathrm{mg} / \mathrm{dl}$. En los animales del grupo II los resultados estaban comprendidos entre 28,5 y 34,4 $\mathrm{mg} / \mathrm{dl}$. En ambos grupos se trataban de cifras no patológicas. El tratamiento estadístico de los datos obtenidos en ambos grupos nos demuestra que no existe una diferencia significativa entre ellos $(p>0,05)$.

La determinación de las fosfatasas alcalinas en los animales del grupo I nos dieron cifras comprendidas entre 116 y $330 \mathrm{U} / 1$. Por su parte, las determinaciones en los animales del grupo II nos dieron cifras entre 70 y $360 \mathrm{U} / 1$. El tratamiento estadístico entre ambos grupos demostró que no existía una diferencia significativa $(p>0,05)$

\section{Estudio radiográfico}

Las radiografías realizadas en el postoperatorio inmediato a los animales intervenidos nos muestran como la zona metáfiso-diafisaria del hueso, donde había sido implantado el material, muestra una zona con aumento de la densidad ósea debida al aspecto radiopaco del material implantado. Este aumento de densidad ósea permanece prácticamente igual durante las primeras semanas que siguen a la intervención y sólo a partir de la décima semana se puede ver como comienza la reabsorción del material implantado disminuyendo la superficie radiopaca que ocupa el material (Figs. 3 y 4). Esta disminución sigue produciéndose progresivamente, de tal manera, que a las veinte semanas de la intervención es francamente notable. Aún así, a las veinte semanas después de la intervención esta disminución no llega al veinticinco por ciento de la superficie que ocupa el material en el postoperato-
rio. 


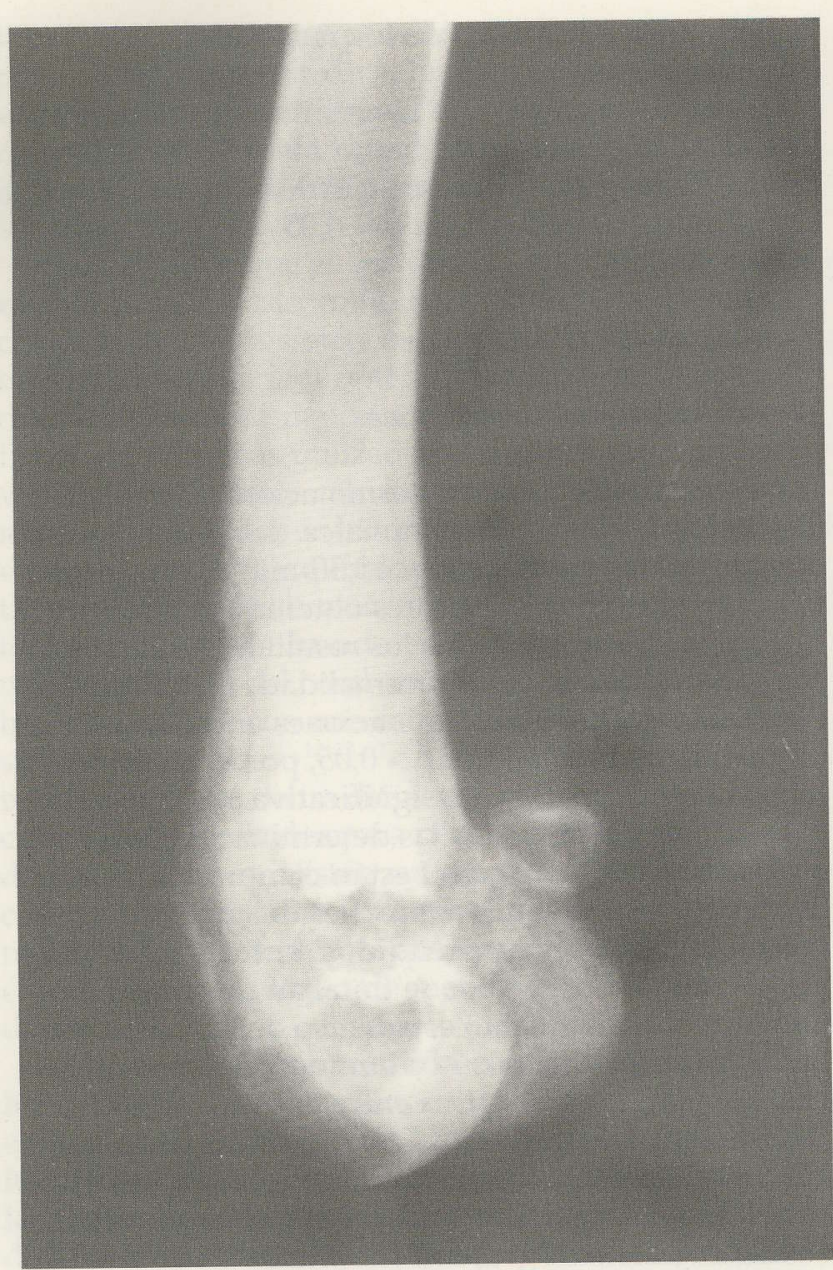

FIG. 3.-Radiografía postoperatoria del fémur del animal de experimentación: zona metáfiso-diafisaria con aumento de densidad ósea correspondiente a la zona del implante del material.

\section{Estudio histológico}

En las preparaciones realizadas a los tres días después de la intervención se puede apreciar como el material implantado presenta los gránulos de hidroxiapatita unidos por una importante red de colágeno (Fig. 5). En la periferia del implante se encuentra tejido hemorrágico que se entremezcla con el material del implante y en algunas zonas aparece un tejido de granulación con abundantes macrófagos. A la semana de la intervención este proceso de progresiva sustitución del material implantado, más concretamente del colágeno, por tejido fibroso cicatricial es más notable. Llama la atención como en las zonas periféricas comienza una osificación del tejido fibroso debido a una importante actividad osteoblástica (Fig. 6), especialmente en zonas cercanas al endostio y con una importante cantidad de vasos. Esta formación de teji-

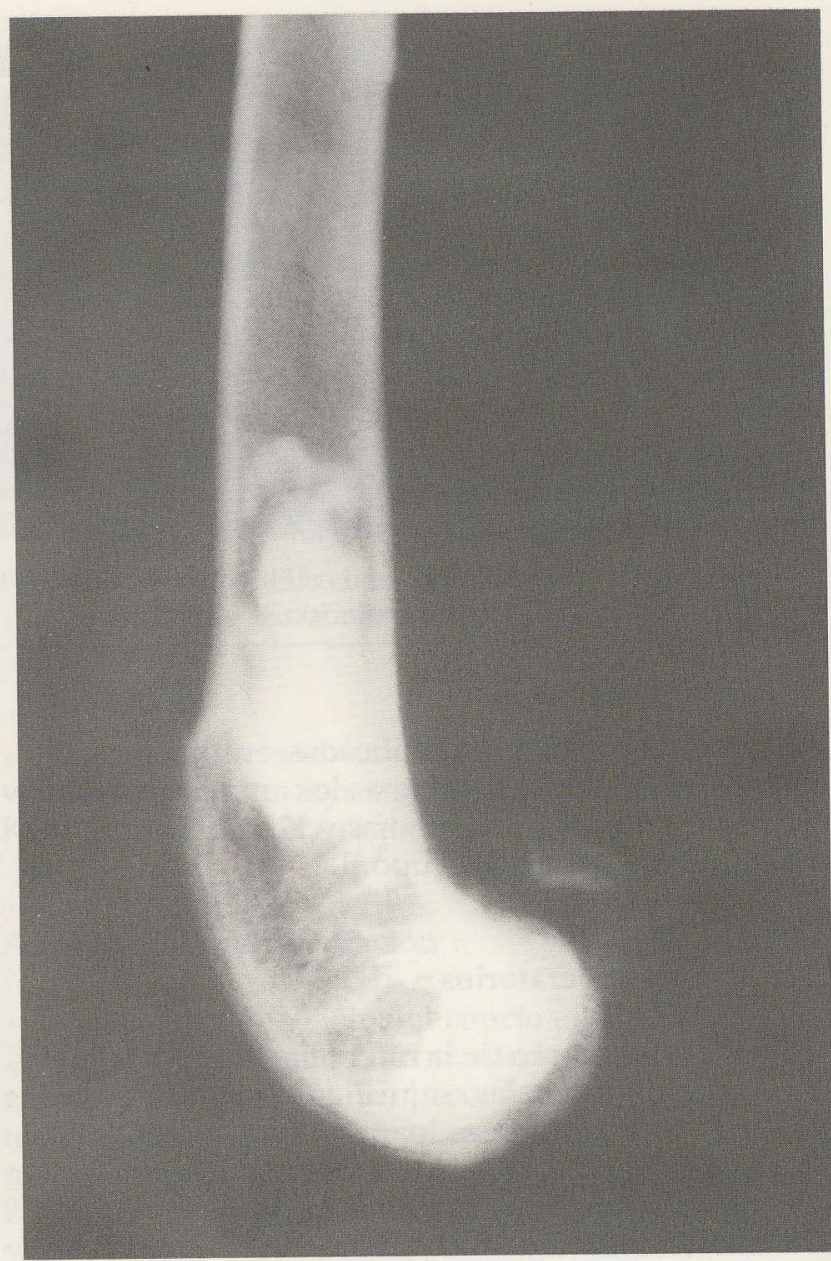

FIG. 4.-Radiografía a las diez semanas del implante. Se aprecia discreta disminución de la zona radiopaca.

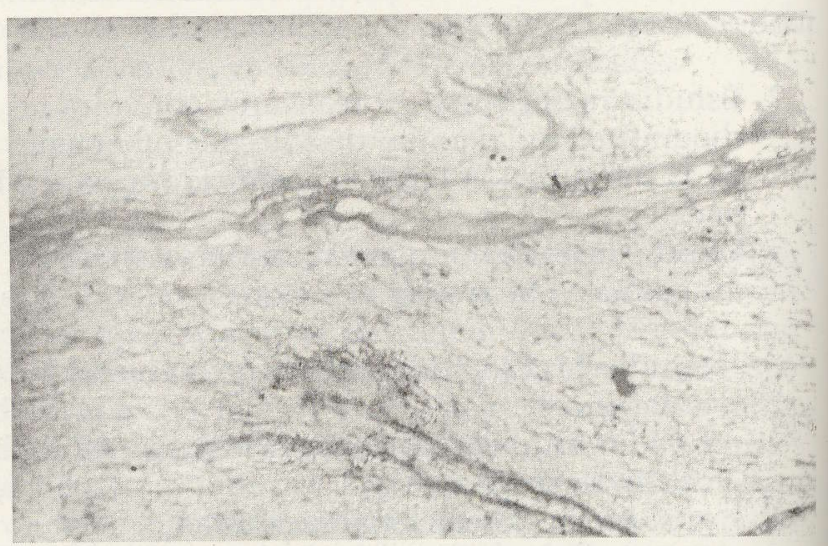

FIG. 5.-MO x 400 hematoxilina-eosina: zona del implante a los 3 días de la intervención. 


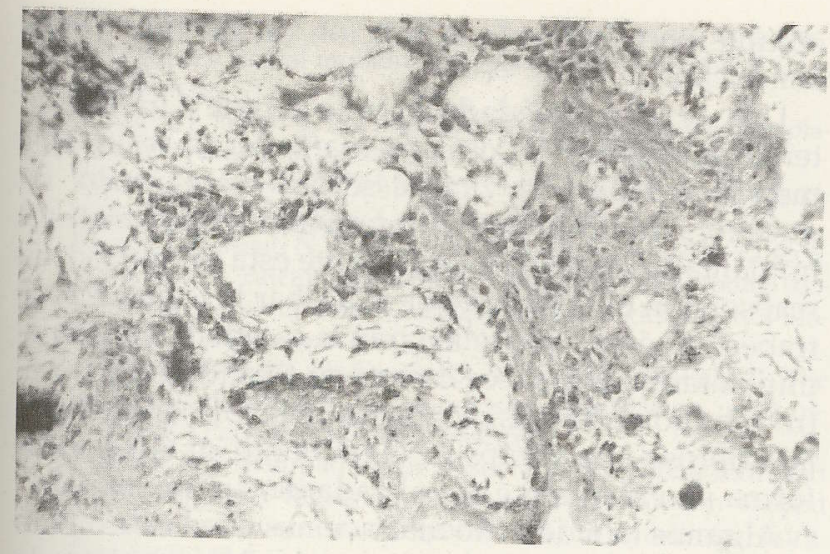

FIG. 6. $-\mathrm{MO} \times 400$ hematoxilina-eosina: a las 2 semanas del implante importante actividad osteoblástica.

do óseo se realiza respetando los cristales de hidroxiapatita, de tal manera, que las trabéculas óseas recién formadas rodearon y dejaron englobados en su interior los cristales de hidroxiapatita. En estas primeras semanas después de la intervención no encontramos reacciones de cuerpo extraño.

Sin embargo, a las seis semanas de la intervención se encontraron zonas donde aparecen células multinucleadas de cuerpo extraño, que tendrían por misión fagocitar cristales de hidroxiapatita. Estas zonas corresponderían a la parte más central del implante, lejos del endostio, y por lo tanto mal vascularizada (Fig. 7).

En el estudio con el microscopio electrónico constataron como en el interior del citoplasma de los macrófagos aparece gran cantidad de fagosomas con restos del material implantado.

A las veinte semanas después de la intervención se constató una gran proliferación de tejiđo óseo recién formado, que fue emergiendo desde el endostio y que

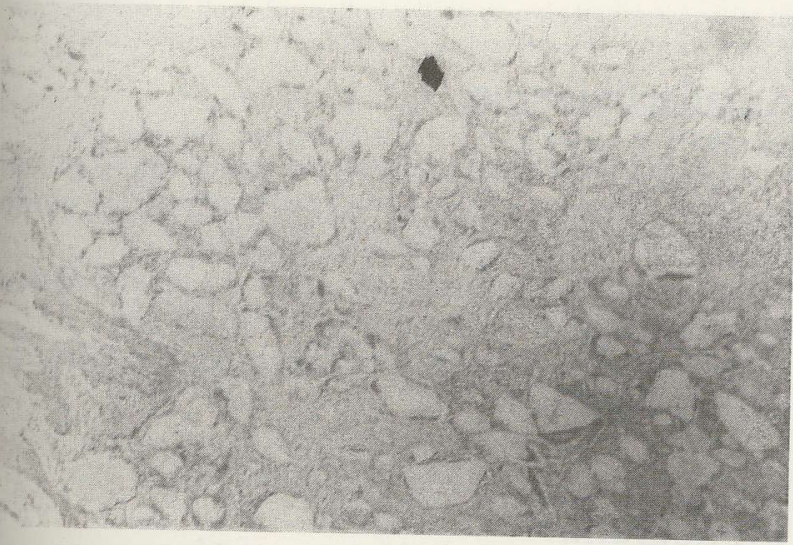

FIG. 7.-MO X 400 hematoxilina-eosina: a las seis semanas zona hipovascularizada del implante con aparición de algunas células gigantes de cuerpo extraño. sustituye al tejido fibroso, englobando a numerosos cristales de hidroxiapatita que se habían implantado (Fig. 8). Sólo en algunas zonas del centro del implante aparece un tejido cicatricial de aspecto denso y con algunas células de cuerpo extraño, sin que sea evidente la formación de tejido óseo.

El estudio histomorfométrico en los animales del grupo II, durante las tres primeras semanas después de la intervención se produjo una rápida reabsorción del material implantado, para proseguir después muy lentamente. Sin embargo, la superficie correspondiente al tejido óseo recién formado es inversamente proporcional a este fenómeno, de tal manera, que desde la intervención y hasta veinte semanas después se produce una importante y progresiva formación de hueso gracias a la gran actividad osteoblástica que se aprecia en el interior del hueso. El tratamiento estadístico de estos parámetros nos demuestran que existe una diferencia estadísticamente significativa.

Por otra parte, el estudio histomorfométrico de la formación de hueso en los animales del grupo I es inferior a la que se produce en los animales del grupo II. El tratamiento estadístico de los resultados de la medición de superficie de hueso formada en los animales del grupo I y grupo II, nos demuestra que existe una diferencia estadísticamente significativa entre los animales de un grupo y otro, siendo mayor la cantidad de hueso formado en los animales del grupo II.

\section{Discusión}

El tratamiento de defectos óseos necesita el uso de gran cantidad de injertos óseos córtico-esponjoso. Esto hace que los cirujanos ortopédicos tengan que recurrir a la utilización del banco de hueso pero esto plantea serios problemas como la infección ${ }^{38}$.

Las cerámicas de fosfatos cálcicos se consideran

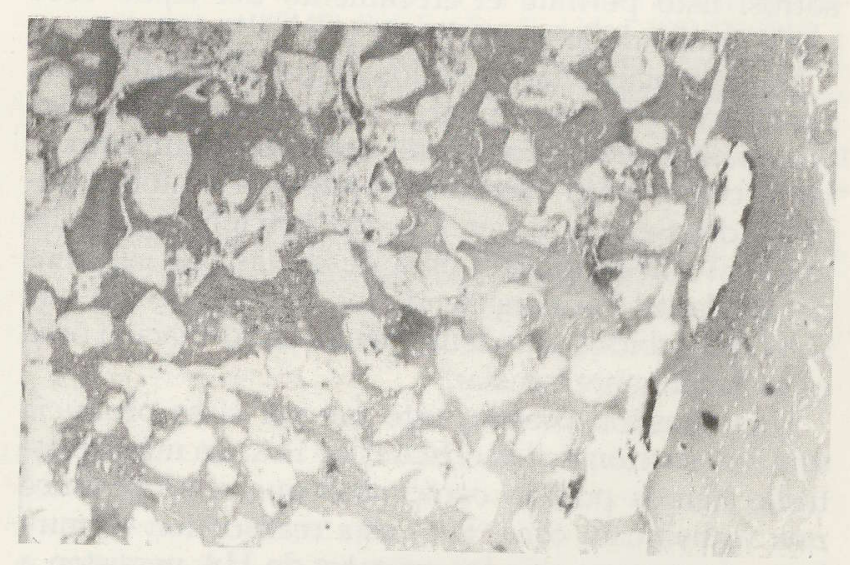

FIG. 8.- MO X 400 tricómico de Masson: a las 20 semanas trabéculas óseas recién formadas rodeando los grastales de hidroxiapatita no reabsorbida. 
materiales bioactivos, según la definición propuesta por Williams en 1987 «como material que induce una actividad biológica específica» ${ }^{42}$. Las cerámicas de fosfato cálcico actúan interaccionando con el hueso reabsorbiéndose, más o menos lentamente dependiendo del tipo y de la porosidad del material 4,5,31. Esto ha hecho que la hidroxiapatita pueda ser considerada como un material biocompatible ${ }^{1,21}$. Por esta razón se ha utilizado como material de relleno cavitario $^{23}$, o de recubrimiento ${ }^{2,26}$.

Los estudios histológicos de los fosfatos cálcicos han demostrado que aunque no son materiales que puedan actuar como osteoinductores, si que actúan como soporte del crecimiento óseo, lo que se ha denominado osteoconducción ${ }^{42}$. La utilización de la hidroxiapatita en forma de granos compactos con una porosidad baja presenta grandes inconvenientes ${ }^{18}$ ya que no permite la formación de las trabéculas óseas recién formadas. En nuestro trabajo, la asociación del colágeno a la hidroxiapatita permite separar los granos de la hidroxiapatita. Hemos podido comprobar como el colágeno se reabsorbe rápidamente permitiendo el normal crecimiento de tejido óseo recién formado entre los gránulos de hidroxiapatita. De esta manera podemos ver las trabéculas óseas formadas entre los gránulos de hidroxiapatita que aún no se han reabsorbido. Esto hace que se mantenga la resistencia ósea del hueso mientras se forma el hueso, para una vez formado el hueso se empieza a reabsorber lentamente la hidroxiapatita, de tal manera que cuando este se ha reabsorbido ya existe un hueso normal.

Para algunos autores la hidroxiapatita es la cerámica que tiene más poder osteogénico según los estudios realizados con microrradiografía ${ }^{22}$, pero por contra la HA tiene una gran estabilidad en el tiempo $^{4,5}$ cosa que se traduce por una muy lenta reabsorción. Esto ha hecho que algunos autores sean partidarios de combinar la HA con otro material de reabsorción más rápido, bien sea las cerámicas bifásicas o combinar el colágeno a la HA como hemos hecho nosotros. Esto permite el crecimiento del tejido óseo permaneciendo los cristales de $\mathrm{HA}^{4,5,14}$.

La evaluación clínica de los implantes es difícil de cuantificar, pero sin embargo los estudios radiográficos, analíticos e histológicos, demuestran un importante crecimiento óseo a expensas del material implantado. Se puede ver una reabsorción rápida del material con formación ósea desde las dos semanas del implante. Permaneciendo los cristales de HA que son reabsorbidos muy lentamente. La formación ósea es esencialmente lamelar.

Una cuestión preocupante fue ver si se producía una reabsorción de los cristales de HA. En nuestro estudio hemos podido comprobar que si se produce una reabsorción ósea. Pero esta reabsorción es muy lenta de manera que los cristales de HA persisten a las 40 semanas después del implante, quedando totalmente rodeados de trabéculas óseas. Esto nos permite asegurar que el material que hemos estudiado cumple perfectamente la función de material osteoconductor.

Una de las propiedades que se le pide a un biomaterial de sustitución ósea es mantener la resistencia mecánica del hueso donde se han implantado. En nuestro estudio hemos comprobado que el material implantado cumple perfectamente esta propiedad. Su reabsorción es tan lenta que al acabar la formación de trabéculas óseas que rellenaran la cavidad, el material implantado permanece casi en su totalidad. En nuestro estudio no hemos comprobado la formación de tejido fibroso que encapsule el implante, ni tampoco se forma una reacción generalizada de cuerpo extraño.

Algunos han descrito alteraciones en el calcio plasmático en animales a los que se les han implantado algunos tipos de materiales ${ }^{25}$. En nuestro estudio no hemos comprobado incremento en las cifras de calcio. Así como tampoco se ha comprobado ningún otro tipo de alteración. No hemos podido hallar diferencias significativas en las determinaciones de calcio ni fósforo en los animales del grupo I y II. Tampoco hemos encontrado efectos de toxicidad en los animales a los que les hemos implantado la HA y colágeno.

\section{Conclusiones}

- La hidroxiapatita asociada al colágeno, permite la regeneración ósea en la cavidad donde ha sido implantada. Podemos pues considerarla como un biomaterial osteoconductor.

- Aunque la hidroxiapatita no actúa como un biomaterial osteoinductor, hemos podido comprobar que actúa favoreciendo la regeneración ósea en las cavidades donde ha sido implantada.

- No se han podido comprobar efectos tóxicos en los animales de experimentación, ocasionados por los materiales implantados.

- La hidroxiapatita es un material de reabsorción muy lenta. Esta reabsorción se produce después de haberse realizado una neoostogénesis cavitaria.

\section{Agradecimientos}

Agradecemos a OSTEO AG su gentil colaboración en este estudio facilitando todo el material necesario de COLLAPAT para realizar el estudio.

Este estudio se ha realizado gracias a la subvención de la beca CICYT (Ref. MAT95-1010-C03-03).

Este estudio se ha realizado dentro del proyecto CITED-95-VIII.6.

\section{Bibliografía}

1. Beirne OR, Grenspan JS. Histologic evaluation of tussie response to hydroxyapatite implanted on human mandibles. Dent Res. 1985;64:1152. 
2. Block MS, Kent JN, Kay JF. Evaluation of hydroxylapatite coated titanium dental implants in dogs. J Oral Maxilofacial Surg. 1987:45:601.

3. Chiroff RT, White E, Roy D, Weber J. Tissue ingrowth of replamineform implants. J Biomed Mater Res 1975;6:29-45.

4. Daculsi G, Iegeros RZ, Mitre D. Cristal dissolution of biological and ceramic apatites. Calcif Tiss Int 1988.

5. Daculsi G, Passuti N, Martin S, Deudon C, legeros RZ, Raher S. Macroporous calcium phosphate ceramic for long bone surgery in humans and dogs. Clinical and histological study. J Biomedical Mat Research. 1990;24:379-396.

6. Doll BA, Towle HJ, Hollinger JO, Reddi AH, Mellonig JT. The osteogenic potential of two composite graft systems using osteogenin. J Periodontal. 1990:61:745-50.

7. Drobeck HP. Histopathologic observations for long term soft tissue responses following implantation of random shaped particles and discs of durapatite. J Oral Maxillofac Surg. 1984;42(3):143-9.

8. Eysel W, Roy DM. Topotactic reaction of aragonite to hydroxylapatite. Z Kristollographic. 1975;141:11-5.

9. Finn R, Brammer JA. Interpositional "grafting» with autogenous bone and coralline hydroxyapatite. J Maxillofac Surg. 1980;8:217-27.

10. Froum S, Stahl SS. Human intraosseus healing responses to the placement of tricalcium phosphate ceramic implants. II. 14 to 18 months. J Periodontol. 1987;58:103-9.

11. Glass DA, Mellonig JT, Towle HJ. Histologic evaluation of bone inductive proteins complexed with coralline hydroxyapatite in an extraskeletal site of the rat. J Periodontol. 1989;60:121-6.

12. Han T, Carranza FA, Kenney EB. Calcium phophate ceramics in dentistry. J West Soc Periodont Abstr. 1984;32:88.

13. Holmes RE. Bone regeneration within a coralline hydroxiapatite implant. Plast Reconst Surg. 1979:63:626-33.

14. Iwano T, Kurosawa H, Murase K y cols. Tissue reaction collagen-coated porous hydroxyapatite. Clin Orthop $n^{-0} 268$. $1991 ; 243-52$.

15. Jarcho M, Bolen CH, Thomas MB, Bobick J, Kau JF, Doremus RH. Hydroxyapatite synthesis and characterization in dense polycristaline form. J Matr Sci. 1976;11:2027-2035.

16. Jarcho M. Calcium phosphate ceramic as hard tissue prosthetics. Clin Orthop. 1981:157:269-77.

17. Jarcho M, Salsbury RL, Thomas MB, Doremus RH. Synthesis and fabrication of beta-tricalcium phosphate ceramics for potential prosthetic applications. J Matr Sci. 1079;14:142-8.

18. Kattagen B. Bone with bone substitutes. Ed. Springer-Verlag. Berlin 1988

19. Kenney EB, Lekovic V, Han J, Carranza Fa, Dimitrejevic B. The use of porous hydroxiapatite implants in periodontal defects. J Periodontol. 1985;56:82-8.

20. Kenney EB, Lekovic V, Sa Ferreira JC, Han T, Dimitrijevic B, Carranza F. Bone formation within porous hydroxyapatite implants in human periodontal defects. J Periodontol. 1986;57:7683.

21. Kent JN, Quinn JH, Zide MF. Alveolar rige augmentation using nonresorbable hydroxyapatite with or without autogenous cancellous bone. J Oral Maxilofac Surg. 1983;41:629.

22. Klein CP, Driessen AA, de Groot K. Biodegradation behavior of various calcium phosphate materials in bone tissue. J Biomed Mater Res. 1983;17:769.
23. Meffert RM, Thomas JR, Hamilton KM. Hydroxyapatite as an alloplastic graft in the treatment of human periodontal osseus defects. J Periodont. 1985;56:63.

24. Metsger JS, Drikell TD, Paulsrud JR. Tricalcium phosphate ceramic-a resorbable bone implant: review and current status. J Am Dent Assoc. 1982;105:1035-8.

25. Morales JJ. Estudio experimental del relleno de cavidades óseas con sulfato cálcico impregnado en gentamicina. Tesis Doctoral. Universidad de Barcelona 1991.

26. Ohno K, Sugimoto A, Shirota T. Histologic finding of apatitetitanium complex dental implants in the jaw of dogs. Oral Surg Oral Med Oral Pathol. 1991;71:426.

27. Reddi AH. Cell biology and biochemistry of endochondral bone development. Coll Res 1981;1:209-26.

28. Reddi AH, Anderson WA. Collagenous bone matrix-induced endochondral ossification and hemopoiesis. J Cell Biol 1976:69:557-572.

29. Redja DA. Tricalcium phosphate as a bone substitute. J Bioeng 1977;1:93-8.

30. Redja DA. Composite materials for hard tissue replacement (Thesis). Amsterdam. The Netherlands: Free Univesity, 1977.

31. Renoij W, Hoogendoorn $\mathrm{H}$, Visser WJ, Lentferink RH, Scmitz MG, Van Ieperen $H$, Oldenburg SJ, Janssen WM, Akkermans LM, Wittebol P. Bioresorption of ceramic strontium 85 labeled calcium phosphate ceramic implants in dog femora. Clin Orthop. 1985;197:272

32. Roy DM, Linnehan S. Hydroxyapatite formed from coral skeleton carbonate by hydrothermal exhange. Nature 1974;247:220-2

33. Sampath TK, Reddi AH. Dissociative extraction and reconstitution of extracellular matrix components involved in local bone differentiation. Proc Natl Acad Sci (USA) 1981;78:7599603.

34. Sampath TK, DeSimone D, Reddi AH. Role of extracellular matrix in bone induction. Exp Cell Res. 1982;142:460-6.

35. Sampath TK, Nathanson M, Reedi AH. In vitro transformation of mesenchymal cells derived from embryonic muscle into cartilage in response to extracellular matrix components of bone. Proc Natl Acad Sci (USA) 1984;81:3419-23.

36. Sampath TK, Reddi AH. Distribution of bone inductive proteins in mineralized and demineralized extracellular matrix. Biochem Biophys Res Comm 1984;119:949-54.

37. Takoaka T, Nakahara $H$, Yoshikáwa $H$, Masuhara $K$, Tsuda T, Ono K. Ectopic bone induction on and in porous hydroxyapatite combined with collagen and bone morphogenetic protein. Clin Orthop 1989;234:250-4.

38. Tomford WW, Starkweather RJ, Goldman MH. A study of the clinical incidence of infection in the use of banked allograft bone. J Bone Joint Surg. 1981;63-A:244.

39. Urist MR, Sato K, Brownell AG y cols. Human bone morphogenetic protein (hBMP). Proc Soc Exp Biol Med. 1983;173:194-9.

40. Urist MR, Lietze A, Dawson E. Beta-tricalcium phosphate delivery system for bone morphogenetic protein. Clin Orthop. 1984;187:277-80.

41. West TL, Brustein DD. Comparison of replamineform coral and bone alloimplants in dog periodontal implants. J Dent Res 1978;57(Spec. Issue);101.

42. Williams DF. Definitions in Biomaterials. Progress in Biomedical Engineering 4. Elsevier, Amsterdam, 1987. 